\title{
Adenosine and Sleep Homeostasis in the Basal Forebrain
}

\author{
Carlos Blanco-Centurion, ${ }^{1}$ Man Xu, ${ }^{1}$ Eric Murillo-Rodriguez, ${ }^{1}$ Dmitry Gerashchenko, ${ }^{1}$ Anjelica M. Shiromani, ${ }^{1}$ \\ Rafael J. Salin-Pascual, ${ }^{1}$ Patrick R. Hof, ${ }^{2}$ and Priyattam J. Shiromani ${ }^{1}$ \\ ${ }^{1}$ West Roxbury Veterans Affairs Medical Center and Harvard Medical School, West Roxbury, Massachusetts 02132, and ${ }^{2}$ Mount Sinai School of Medicine, \\ New York, New York 10029
}

It is currently hypothesized that the drive to sleep is determined by the activity of the basal forebrain (BF) cholinergic neurons, which release adenosine $(\mathrm{AD})$, perhaps because of increased metabolic activity associated with the neuronal discharge during waking, and the accumulating $\mathrm{AD}$ begins to inhibit these neurons so that sleep-active neurons can become active. This hypothesis grew from the observation that $\mathrm{AD}$ induces sleep and $\mathrm{AD}$ levels increase with wake in the basal forebrain, but surprisingly it still remains untested. Here we directly test whether the basal forebrain cholinergic neurons are central to the AD regulation of sleep drive by administering 192-IgGsaporin to lesion the $\mathrm{BF}$ cholinergic neurons and then measuring $\mathrm{AD}$ levels in the $\mathrm{BF}$. In rats with $95 \%$ lesion of the $\mathrm{BF}$ cholinergic neurons, $\mathrm{AD}$ levels in the BF did not increase with $6 \mathrm{~h}$ of prolonged waking. However, the lesioned rats had intact sleep drive after 6 and $12 \mathrm{~h}$ of prolonged waking, indicating that the $\mathrm{AD}$ accumulation in the $\mathrm{BF}$ is not necessary for sleep drive. Next we determined that, in the absence of the $\mathrm{BF}$ cholinergic neurons, the selective adenosine $\mathrm{A}_{1}$ receptor agonist N6-cyclohexyladenosine, administered to the $\mathrm{BF}$, continued to be effective in inducing sleep, indicating that the BF cholinergic neurons are not essential to sleep induction. Thus, neither the activity of the $\mathrm{BF}$ cholinergic neurons nor the accumulation of $\mathrm{AD}$ in the $\mathrm{BF}$ during wake is necessary for sleep drive.

Key words: adenosine; purines; basal forebrain; sleep; REM sleep; homeostasis; microdialysis

\section{Introduction}

The drive to sleep begins with the onset of wake and dissipates slowly with sleep. Endogenous sleep factors acting on specific neurons in the brain are hypothesized to regulate the waxing and waning of the sleep drive (Porkka-Heiskanen, 1999; PorkkaHeiskanen et al., 2002). One such sleep factor is adenosine (AD), a naturally occurring purine nucleoside present in all cells and released as a neurotransmitter (Fredholm, 1995). AD concentrations increase with cellular metabolism (Latini and Pedata, 2001), and, because brain metabolism increases during waking, AD levels also rise. It is hypothesized that $\mathrm{AD}$ accumulates during wake, and, because it accumulates, it inhibits neural activity in wakepromoting brain regions (Rainnie et al., 1994; Porkka-Heiskanen et al., 1997). One such brain region in which $\mathrm{AD}$ is hypothesized to be effective in inducing sleep is the basal forebrain (BF) (Porkka-Heiskanen et al., 2000).

The BF is the rostralmost extension of a distributed network of neurons implicated in regulating wake (Szymusiak et al., 2000). The BF contains a mixed phenotype of neurons, some of which are cholinergic (Zaborszky and Duque, 2003). The cholinergic BF neurons are active during wake and rapid eye movement (REM) sleep as determined by juxtacellular recording (Manns et al.,

Received Feb. 10, 2006; revised June 20, 2006; accepted June 20, 2006.

This work was supported by National Institutes of Health Grants NS30140, NS52287, AG15853, and MH55772 and Medical Research Service of the Department of Veterans Affairs. We thank Jill Winston and Samara Shiromani for providing excellent technical assistance and Elizabeth Winston for analyzing the sleep data.

Correspondence should be addressed to Dr. Priyattam J. Shiromani, Department of Neurology, Harvard Medical School and Veterans Affairs Medical Center, Building 3, Room 2C109, 1400 VFW Parkway, West Roxbury, MA 02132. E-mail:pshiromani@hms.harvard.edu.

DOI:10.1523/JNEUROSCI.2181-06.2006

Copyright $\odot 2006$ Society for Neuroscience $\quad$ 0270-6474/06/268092-09\$15.00/0
2000; Lee et al., 2005a) and c-Fos activity (Greco et al., 2000). Moreover, acetylcholine is released in the cortex during waking and REM sleep (Celesia and Jasper, 1966; Szerb, 1967; Jasper and Tessier, 1971; Rasmusson et al., 1992). Current models (Semba, 2000; Jones, 2003, 2004; Gerashchenko and Shiromani, 2004) suggest that the cholinergic BF neurons are driven by ascending influences from other arousal populations, such as neurons from the mesopontine region, histamine tuberomammillary nucleus, and the hypocretin neurons in the lateral hypothalamus. During wake, the increased activity of the cholinergic BF neurons is hypothesized to release $\mathrm{AD}$, and, in turn, these neurons are shut off by the localized buildup of AD (Strecker et al., 2000).

Consistent with such a hypothesis, systemic or intracerebroventricular administration of $\mathrm{AD}$ promotes sleep and decreases the waking state (Radulovacki et al., 1984; Ticho and Radulovacki, 1991). In cats (Porkka-Heiskanen et al., 1997) and rats (Murillo-Rodriguez et al., 2004), extracellular concentrations of $\mathrm{AD}$ in the $\mathrm{BF}$ increase with prolonged waking and then decline with subsequent sleep. In vivo microdialysis perfusion of $\mathrm{AD}$ into brain sites reduces the waking state and increases slow-wave sleep (Portas et al., 1997). Inhibition of AD transport in the BF leads to increased extracellular levels of $\mathrm{AD}$ and also results in increased sleep (Porkka-Heiskanen et al., 1997). Conversely, caffeine, consumed in the form of tea or coffee, is a nonspecific AD antagonist that potently increases waking and decreases sleep (Fredholm, 1995; Wyatt et al., 2004; LaJambe et al., 2005).

Although in the BF adenosine levels rise and fall with wake and sleep, would $\mathrm{AD}$ levels increase with prolonged waking if the cholinergic neurons were destroyed? This is an important question in the overall model of $\mathrm{AD}-\mathrm{BF}$ regulation of sleep-waking that surprisingly has never been investigated but that can be an- 
swered by using 192-IgG-saporin (192-IgG-Sap) to lesion the BF cholinergic neurons and measuring adenosine in the $\mathrm{BF}$ that is devoid of cholinergic neurons. We then investigate whether sleep homeostasis is also affected when the cholinergic BF neurons are removed.

\section{Materials and Methods \\ Animals}

Sprague Dawley rats weighing $250 \mathrm{~g}$ were obtained from the vendor (Charles River Laboratories, Wilmington, MA), housed at a constant temperature $\left(21 \pm 1^{\circ} \mathrm{C}\right)$ under a controlled light/dark cycle (lights on from 7:00 A.M. to 7:00 P.M.), and provided with food and water ad libitum.

\section{Surgery and 192-IgG-Sap}

While under deep anesthesia [mixture of acepromazine $(0.75 \mathrm{mg} / \mathrm{kg})$, xylazine $(2.5 \mathrm{mg} / \mathrm{kg})$, and ketamine $(22 \mathrm{mg} / \mathrm{kg})$ administered intramuscularly], saline $(n=26)$ or 192-IgG-Sap $(n=30 ; 2 \mu \mathrm{g} / \mu \mathrm{l}$, total volume injected of $3 \mu \mathrm{l}$ ) was placed into the lateral ventricle via the gravity method. The cannula was left in place for $5 \mathrm{~min}$ and then withdrawn slowly.

At this time, cortical sleep recording electrodes were implanted as described previously (Shiromani et al., 2000). Briefly, four stainless-steel screws were fixed to the parietal and occipital bones and were used to record the electroencephalogram (EEG). Two miniature screws were inserted $2 \mathrm{~mm}$ on either side of the sagittal sinus and $3 \mathrm{~mm}$ anterior to bregma (frontal cortex). The other two screws were located $3 \mathrm{~mm}$ on either side of the sagittal sinus and $6 \mathrm{~mm}$ behind bregma (occipital cortex). The EEG was recorded from two contralateral screws (frontaloccipital). Two stainless-steel flexible multiwire electrodes inserted into the nuchal muscles were used to monitor the electromyogram (EMG).

At this time, a guide cannula [IC guide; BioAnalytical Systems (BAS), West Lafayette, IN] was placed stereotaxically into the basal forebrain [target coordinates in $\mathrm{mm}$ : anterior, -0.35 ; lateral, 2.0; vertical, 7.5 (Paxinos and Watson, 2006)]. The cannula was for microdialysis and measurements of extracellular adenosine. The guide cannula was then fixed onto the skull with a thin layer of dental cement. All electrodes were placed in a six-pin plastic plug and secured onto the skull using dental cement.

One day after surgery, the animals were attached to the electroencephalographic recording leads and sleep EEG recordings were started. All rats were treated in accordance with the American Association for Accreditation of Laboratory Animal Care policy on care and use of laboratory animals. All efforts were done to minimize animal suffering and to minimize the number of animals in the experiments. All experiments were conducted with food and water available ad libitum.

\section{Analyses of sleep recordings}

In all rats, a $48 \mathrm{~h}$ sleep recording was made 2 weeks after surgery. Contralateral frontal-occipital EEG screw electrodes were used for EEG acquisition. The EEG data were filtered at $70 \mathrm{~Hz}$ (low-pass filter) and $0.3 \mathrm{~Hz}$ (high-pass filter) using three different Grass Instruments (Quincy, MA) electroencephalographs and continuously sampled at $128 \mathrm{~Hz}$. The EEG data recordings were scored manually on a computer (Icelus software; Dr. Mark Opp, University of Michigan, Ann Arbor, MI) in $12 \mathrm{~s}$ epochs for wake, non-REM sleep, and REM sleep. The wake state was identified by the presence of desynchronized EEG and high EMG activity. NonREM sleep consisted of high-amplitude slow waves together with a low EMG tone relative to awake. REM sleep was identified by the presence of regular theta activity coupled with low EMG relative to non-REM sleep.

\section{Histological verification of probe location}

and immunocytochemistry

Animals were killed with a lethal dose of pentobarbital and perfused transcardially with $0.9 \%$ saline solution, followed by $10 \%$ formaldehyde. The brains were removed and postfixed overnight in $4 \%$ formaldehyde, followed by $30 \%$ sucrose/ 0.1 m PBS for $48 \mathrm{~h}$. The brains were cut (frozen sections, $30 \mu \mathrm{m}$, coronal) and collected in 1:5 serial order. The tissue sections were processed for identifying choline acetyltransferase- immunoreactive (ChAT-IR) neurons, and the sections were lightly counterstained with neutral red to allow better visualization of the cannula track and surrounding regions. Briefly, tissue sections were incubated overnight (room temperature) in goat anti-ChAT (AB 144P, 1:4000 dilution; Chemicon, Temecula, CA). The next day, the tissue was exposed to an avidin-biotin secondary antibody $(1 \mathrm{~h})$, followed by an avidin-biotinylated peroxidase complex $(1 \mathrm{~h})$. The peroxidase reaction was developed with $3^{\prime}$-diaminobenzidine (with nickel chloride; Vector Laboratories, Burlingame, CA). The concentrations of primary antibodies were optimized to permit clear visualization of each product. The probe location was plotted on drawings of the rat brain (Paxinos and Watson, 2006) using camera lucida methods.

\section{Tally of ChAT-IR neurons}

One observer blind to the type of drug and site of injection counted all of the ChAT-IR somata on the ipsilateral (microdialysis sampling side) and the contralateral sides. ChAT-positive neurons were counted in the medial septum (MS), horizontal (HDB) and vertical (VDB) limbs of the diagonal bands of Broca, the magnocellular preoptic nucleus (MCPO), and the substantia innominata (SI). In saline rats, the Nissl and ChAT neurons demarcated the boundaries, whereas in the lesion rats, boundaries were determined using the Nissl stain. At least 12 sections encompassing the cholinergic neurons in these groups were examined, and all ChAT-IR somata were counted using a grid $(10 \times 10$ grid; $25 \times$ objective).

\section{Statistical analysis}

The data were analyzed using repeated-measures ANOVA [SPSS (SPSS, Chicago, IL) or SigmaStat (Systat Software, Point Richmond, CA)] with post hoc Tukey's test $(p<0.05)$ and paired or independent $t$ tests when appropriate with Bonferroni's corrections.

\section{Experiment 1: extracellular levels of AD in 192-IgG-Sap \\ lesioned rats}

Animals. Thirteen rats (saline, $n=6$; 192-IgG-Sap, $n=7$ ) were used in this experiment.

Microdialysis sampling procedures. Three weeks after surgery, the microdialysis probe ( $1 \mathrm{~mm}$ length, polyacrylonitrile, molecular weight cutoff of 30,000 Da, $340 \mu \mathrm{m}$ outer diameter; BAS) was inserted through the guide cannula into the target structure at 7:00 A.M., and the tissue was allowed to stabilize for $24 \mathrm{~h}$. During this period, artificial CSF (aCSF) (in mm: $147 \mathrm{NaCl}, 3 \mathrm{KCl}, 1.2 \mathrm{CaCl}$, and $1.0 \mathrm{MgCl}, \mathrm{pH} 7.2$ ) was perfused continuously. In a previous experiment (Murillo-Rodriguez et al., 2004), we determined that it took $\sim 6-7 \mathrm{~h}$ after probe insertion for the AD levels to stabilize. Artificial CSF was perfused at a flow rate of $0.25 \mu \mathrm{l} / \mathrm{min}$.

The following day, the animals were kept awake for $6 \mathrm{~h}$ (starting at Zeitgeber time 6) by lightly tapping the cage or introducing novel objects into the cage whenever the rats showed EEG or behavioral signs of sleep. Samples $(15 \mu \mathrm{l})$ were collected at the start of the sleep deprivation period and at $1 \mathrm{~h}$ intervals for $6 \mathrm{~h}$. The samples were collected on ice and then frozen until HPLC analysis. The personnel involved in keeping the rats awake did not know which rats were given saline or the saporin toxin.

Neurochemical analysis of adenosine. The samples were injected into an high-performance liquid chromatograph (BAS) for purine analysis. The mobile phase consisted of $7 \mathrm{~mm} \mathrm{NaH}_{2} \mathrm{PO}_{4}$, pH 3.0, plus 3.5\% $\mathrm{CH}_{3} \mathrm{OH}$. Separation was achieved by a BAS Microbore column (octadecyl silica, 3 $\mu \mathrm{m}, 100 \times 1 \mathrm{~mm}$; BAS) attached directly to the injector (CC-5e; BAS). Purine concentrations were then obtained by a UV detector set to a wavelength of $254 \mathrm{~nm}$ (UV-116A; BAS). Chromatographic data were recorded in a personal computer, and peak heights of $\mathrm{AD}$ in microdialysis samples were compared with standards using the chromatograph report software (BAS).

\section{Experiment 2: evaluation of sleep homeostasis}

Animals. The sample size for the $6 \mathrm{~h}$ sleep deprivation protocol was as follows: saline, $n=6$; 192-IgG-Sap, $n=7$. The sample size for the $12 \mathrm{~h}$ sleep deprivation protocol was as follows: saline, $n=5$; 192 IgG-Sap, $n=$ 7. Separate groups of rats were used in these two sleep deprivation studies.

Six and $12 \mathrm{~h}$ sleep deprivation. After obtaining a $48 \mathrm{~h}$ sleep recording, 
separate groups of rats were kept awake for $6 \mathrm{~h}$ (last $6 \mathrm{~h}$ of lights-on period) or $12 \mathrm{~h}$ (entire lights-on period) by gentle handling as described in experiment 1 . At the end of the prolonged waking period, the rats were allowed to sleep undisturbed, and sleep EEG recordings were made for $24 \mathrm{~h}$.

Rodent multiple sleep latency test. The sample size for this study was as follows: saline, $n=7$; 192-IgG-Sap, $n=8$. The rats were the same as used in the $6 \mathrm{~h}$ sleep deprivation paradigm, but the multiple sleep latency test (MSLT) experiment was conducted 1 week before the $6 \mathrm{~h}$ sleep deprivation study. In the MSLT paradigm, the rats were kept awake for 20 min beginning at $2 \mathrm{~h}$ after the start of the lights-on period (Zeitgeber time 2) and then allowed to sleep undisturbed for $20 \mathrm{~min}$. The alternating 20 min periods of wake followed by 20 min periods of sleep were continued until the end of the lights-on period, when the rats were allowed to sleep undisturbed. Sleep was recorded throughout the test and for $12 \mathrm{~h}$ after the end of the test. Previously, this test was used to measure REM sleep propensity in a genetic line of rats (Shiromani et al., 1991). During the 20 min sleep periods, the latency to the first non-REM sleep bout ( $2 \mathrm{~min}$ of non-REM sleep) and REM sleep bout ( $\geq 24$ s, i.e., two $12 \mathrm{~s}$ epochs) were determined.

Spectral analysis of the EEG for computation of delta power. The EEG data of rats deprived of sleep for $6 \mathrm{~h}$ was analyzed for changes in delta power $(0.3-4 \mathrm{~Hz})$. The data from the $12 \mathrm{~h}$ sleep deprivation study could not be used because two different Grass Instruments EEG machines were used to collect the data, which caused wide variations in the amplitude of the EEG. Frontal-parietal (contralateral hemispheres) EEG screw electrodes were used for EEG acquisition. The data were filtered at $70 \mathrm{~Hz}$ (low-pass filter) and $0.3 \mathrm{~Hz}$ (high-pass filter) using a Grass Instruments electroencephalograph and continuously sampled at $128 \mathrm{~Hz}$ by a $486-$ Intel microprocessor computer with an analog-to-digital board (National Instruments, Austin, TX). A fast Fourier analysis was performed using the Icelus program (Dr. Mark Opp). Only non-REM sleep was analyzed for changes in delta power.

Experiment 3: effects of the adenosine $A_{1} / A_{2}$ receptor agonist N6-cyclohexyladenosine on sleep

Animals. The sample size for the saline group was as follows: $\mathrm{aCSF}, n=9$; N6-cyclohexyladenosine (CHA) at $10 \mu \mathrm{M}, n=7$; CHA at $25 \mu \mathrm{M}, n=9$; $\mathrm{CHA}$ at $100 \mu \mathrm{M}, n=9$. The sample size for the 192-IgG-Sap group was as follows: aCSF, $n=12$; CHA at $10 \mu \mathrm{M}, n=5$; CHA at $25 \mu \mathrm{M}, n=12$; CHA at $100 \mu \mathrm{M}, n=12$.

Drug infusion paradigm. Two weeks after surgery, a microdialysis probe was inserted and allowed to stabilize for $24 \mathrm{~h}$. At 7:00 P.M. (beginning of lights-off period), aCSF or CHA $(10,25$, or $100 \mu \mathrm{M})$ was infused via the microdialysis probe into the basal forebrain (flow rate of 0.25 $\mu \mathrm{l} / \mathrm{min})$. The CHA was dissolved in aCSF and infused throughout the night cycle. The different concentrations of CHA and aCSF were infused in a counterbalanced order to prevent order effects.

\section{Results \\ Basal forebrain cholinergic neuronal cell loss after 192-IgG-Sap}

Five rats administered 192-IgG-Sap were excluded from the study because they had little or no loss of BF cholinergic neurons. Table 1 summarizes the average numbers of ChAT-IR neurons in the BF in saline-treated $(n=21)$ and 192-IgG-Sap-treated $(n=$ $25)$ rats. Compared with saline rats, there was a significant decline $(-95 \% ; F=593.42 ; p<0.001)$ in the overall number of BF cholinergic neurons in rats administered 192-IgG-Sap. The BF cholinergic neuronal populations were counted separately, and there was a significant cholinergic neuronal loss in the MS $(-98 \%), \mathrm{VDB}(-98 \%), \mathrm{HDB}(-98.5 \%), \mathrm{MCPO}(\sim 100 \%)$, and SI $(-44 \%)$. A subpopulation of neurons in the SI does not contain the p75 NGF receptor and are not killed by the 192-IgG-Sap (Heckers et al., 1994).

\section{Experiment 1: extracellular levels of AD in 192-IgG-Sap lesioned rats}

Figure 1 depicts the location of the microdialysis cannula in representative saline and 192-IgG-Sap lesioned rats. The cannula was localized within the cholinergic zone of the $\mathrm{MCPO}$ in which AD levels previously (Murillo-Rodriguez et al., 2004) increased in response to $6 \mathrm{~h}$ sleep deprivation in rats.

Figure 2 summarizes the effects of sleep deprivation on $\mathrm{AD}$ levels in the BF. Consistent with observations in cats (PorkkaHeiskanen et al., 1997) and our previous study in rats (MurilloRodriguez et al., 2004), AD levels increased in response to sleep deprivation in saline rats (repeated-measures ANOVA; $F=9.98$, $\mathrm{df}=3,15 ; p<0.001$ ) but not in rats lesioned with 192-IgG-Sap $(F=0.97)$. The saline rats had a significantly higher level of $\mathrm{AD}$ during the $6 \mathrm{~h}$ sleep deprivation period compared with the lesioned rats $(F=11.98 ; \mathrm{df}=1,33 ; p<0.002)$.

\section{Experiment 2: evaluation of sleep homeostasis}

If AD levels do not increase with prolonged waking in 192-IgGSap lesioned rats, is sleep homeostasis deficient in these rats? Keeping the rats awake for 6 or $12 \mathrm{~h}$ and then measuring sleep investigated this. Table 2 summarizes the sleep-wake data during the first $12 \mathrm{~h}$ of recovery sleep after 6 and $12 \mathrm{~h}$ of total sleep deprivation. Both the saline and 192-IgG-Sap rats had a similar robust sleep rebound in response to the sleep deprivation. During the subsequent $12 \mathrm{~h}$, sleep levels were also similar between the two groups, indicating that there were no long-lasting consequences of sleep loss in the lesioned rats (Table 3).

We probed the data further to determine whether there was any difference in the rate of accumulation of sleep debt and the recovery from it. We calculated the cumulative change in the hourly amount of wake, non-REM sleep, and REM sleep during the sleep deprivation period and the recovery sleep. The saline and 192-IgG-Sap lesioned rats had a similar rate of loss of sleep during the $6 \mathrm{~h}$ (Fig. 3, left) and $12 \mathrm{~h}$ (Fig. 3, right) period of sleep deprivation, with both groups reaching the same level of sleep debt at the end of the sleep deprivation period. During the subsequent recovery sleep, the rate of increase in non-REM and REM sleep in the 192-IgG-Sap lesioned rats was similar to the saline rats, indicating an intact homeostatic response to 6 and $12 \mathrm{~h}$ sleep loss in the lesioned rats.

We also assessed the power in the EEG after $6 \mathrm{~h}$ of sleep deprivation because it has been theorized that high EEG delta power after sleep loss is an electrophysiological indicator of sleep drive (Borbely et al., 1984). Figure 4 summarizes the increase in delta power in both the lesioned and control rats during the first $2 \mathrm{~h}$ of sleep after $6 \mathrm{~h}$ of total sleep deprivation, indicating intact sleep drive in the lesioned rats.

Next, we used an MSLT to further evaluate the sleep drive. In humans, an MSLT provides an index of sleep drive (Carskadon et al., 1986), the rationale being that an individual will fall asleep very quickly if the drive to sleep is high. We adapted this paradigm to test for sleep drive in rodents (Shiromani et al., 1991). Here we found that the lesioned rats fell asleep as quickly as the 

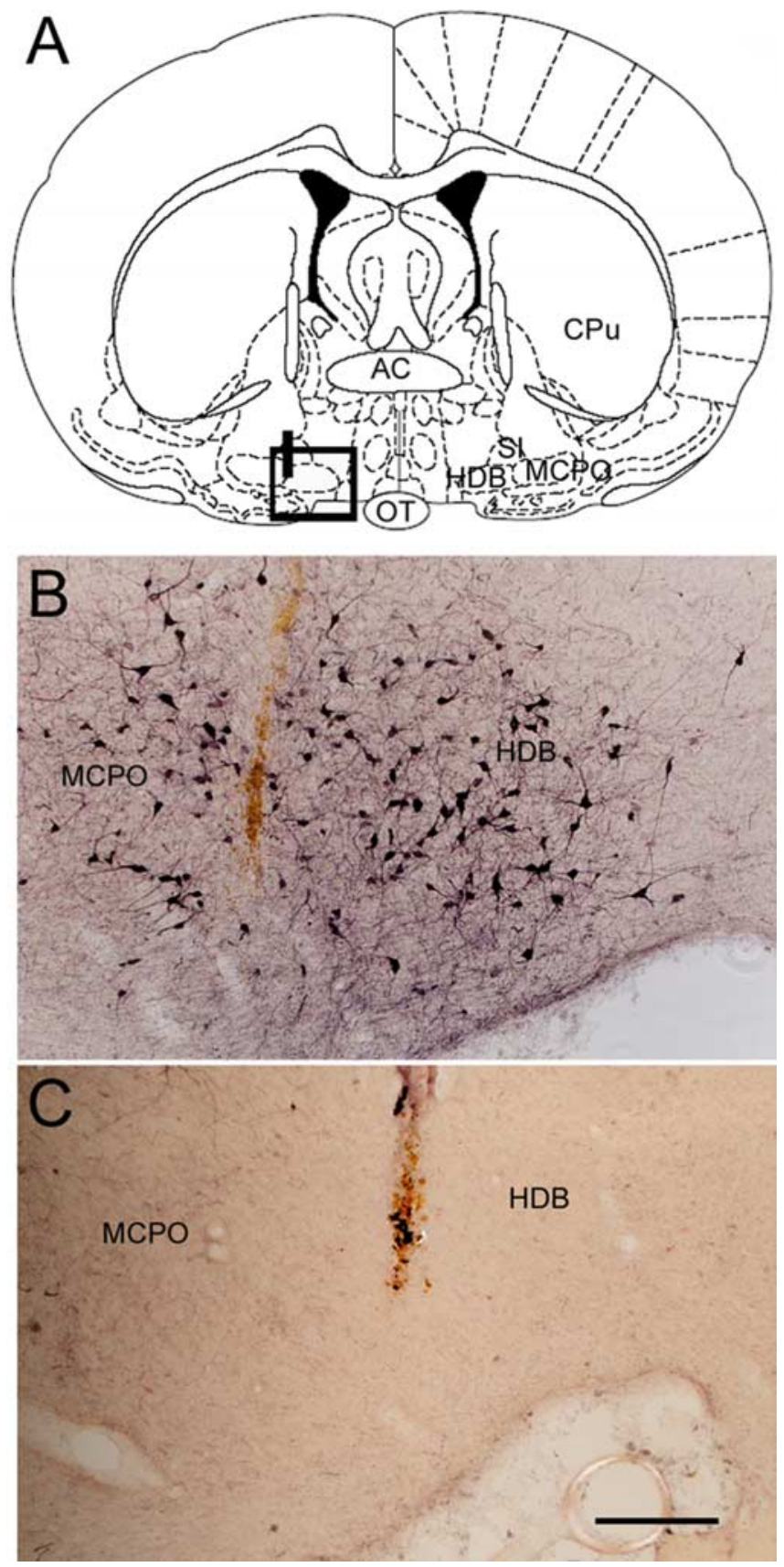

Figure 1. Localization of the microdialysis probe in the basal forebrain. $\boldsymbol{A}$ is a schematic figure from the rat brain atlas of Paxinos and Watson (2006), and the location of the microdialysis probe is depicted by a small black rectangle. The larger rectangle represents the area depicted by the photomicrographs in $\boldsymbol{B}$ and $\boldsymbol{C}$. $\boldsymbol{B}$, Photomicrograph of the track of the microdialysis probe in the basal forebrain of a representative saline control rat with the tip of the probe surrounded by cholinergic neurons. C, Photomicrograph of the track in a representative rat administered 192-lgG-Sap, which kills the BF cholinergic neurons. AC, Anterior commissure; CPu, caudate-putamen; 0T, optic tract. Scale bar, $200 \mu \mathrm{m}$.

control rats, indicating an intact sleep drive in the lesioned rats (Fig. 5).

Figure 6 summarizes the overall levels of sleep in rats with 192-IgG-Sap lesions. Consistent with previous experiments (Bassant et al., 1995; Kapas et al., 1996), there was no change in overall levels of wake, non-REM sleep, or REM sleep (Fig. 6; Tables 4, 5).

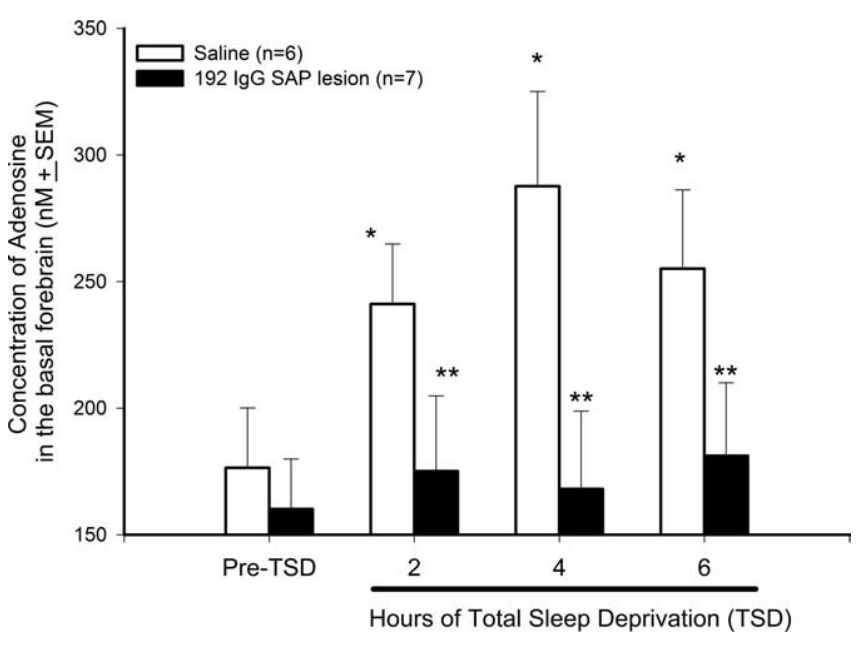

Figure 2. Adenosine levels in the basal forebrain during $6 \mathrm{~h}$ of total sleep deprivation (TSD). Adenosine levels (mean \pm SEM) in the basal forebrain in saline control rats and rats administered 192-IgG-Sap to lesion the basal forebrain cholinergic neurons. AD was collected from the basal forebrain using microdialysis methods and measured via HPLC analysis. Samples $(15 \mu \mathrm{l}$ total volume collected) from the basal forebrain were collected at the start of the hour. Samples were collected for the $1 \mathrm{~h}$ before the start of the sleep deprivation and at each hour during the sleep deprivation. The data during the sleep deprivation period was averaged into $2 \mathrm{~h}$ blocks. ${ }^{*} p<0.001$, significant difference compared with pre-total sleep deprivation; ${ }^{* *} p<0.002$, significant difference compared with the saline group.

Table 2. Average \pm SEM percentage of REM sleep, non-REM sleep, and wake during the first $12 \mathrm{~h}$ of recovery sleep after 6 and $12 \mathrm{~h}$ of total sleep deprivation

\begin{tabular}{llll}
\hline & \multicolumn{4}{l}{ First 12 h of recovery sleep after TSD } \\
\cline { 2 - 4 } & REM & NREM & Wake \\
\hline 6h TSD & & & \\
$\quad$ Saline $(n=7)$ & $12.37(1.15)$ & $29.64(2.12)$ & $57.99(2.9)$ \\
$\quad$ 192-IgG-Sap $(n=6)$ & $13.41(1.17)$ & $32.0(1.87)$ & $54.59(2.72)$ \\
12 h TSD & & & \\
$\quad$ Saline $(n=5)$ & $13.74(1.39)$ & $44.21(2.41)$ & $41.48(3.14)$ \\
192-IgG-Sap $(n=7)$ & $12.19(1.48)$ & $42.13(4.56)$ & $45.67(5.48)$ \\
\hline
\end{tabular}

Table 3. Average \pm SEM percentage of REM sleep, non-REM sleep, and wake during the second $12 \mathrm{~h}$ of recovery sleep after 6 and $12 \mathrm{~h}$ of total sleep deprivation

\begin{tabular}{llll}
\hline & \multicolumn{3}{l}{ Second 12h of recovery sleep after TSD } \\
\cline { 2 - 4 } & REM & NREM & Wake \\
\hline 6h TSD & $18.43(0.79)$ & $53.38(1.51)$ & $28.19(1.98)$ \\
$\quad$ Saline $(n=7)$ & $16.69(0.68)$ & $58.95(1.36)$ & $24.35(1.65)$ \\
192-IgG-Sap $(n=6)$ & & & \\
12 h TSD & $14.72(0.96)$ & $61.21(1.51)$ & $24.09(1.88)$ \\
$\quad$ Saline $(n=5)$ & $14.12(2.12)$ & $57.43(3.68)$ & $28.46(5.25)$ \\
192-IgG-Sap $(n=7)$ & & &
\end{tabular}

TSD, Total sleep deprivation.

\section{Experiment 3: effects of the $\mathrm{AD} \mathrm{A}_{1}$ receptor agonist $\mathrm{CHA}$ on sleep}

Because the lesioned rats have an intact sleep drive although $\mathrm{AD}$ levels do not increase with waking, we wondered whether the noncholinergic neurons in the $\mathrm{BF}$ were responsible for maintaining the sleep drive. In previous experiments, the adenosine $A_{1}$ receptor agonist CHA induced sleep in the BF (Strecker et al., 2000; Murillo-Rodriguez et al., 2004) in a dose-dependent manner. Therefore, here CHA was infused via reverse microdialysis into the BF of saline and lesioned rats. Compared with aCSF, in both the saline control and lesioned rats, there was a significant 
decrease in wake with $100 \mu \mathrm{M}$ CHA and an increase in non-REM sleep in response to 25 and $100 \mu \mathrm{M}$ CHA during the $12 \mathrm{~h}$ lights-off period when the drugs were administered (Fig. 7).

\section{Discussion}

The hypothesis (Porkka-Heiskanen, 1999; Strecker et al., 2000; Porkka-Heiskanen et al., 2002) that $\mathrm{AD}$ released from the $\mathrm{BF}$ cholinergic neurons during waking is responsible for dictating sleep homeostasis was not supported by this study because rats with $95 \%$ loss of the BF cholinergic neurons had intact sleep homeostasis without an increase in $\mathrm{BF} \mathrm{AD}$ levels. Moreover, the $\mathrm{AD} \mathrm{A}_{1}$ receptor agonist $\mathrm{CHA}$ induced sleep in lesioned rats to the same extent as in controls, indicating that the cholinergic neurons in the $\mathrm{BF}$ are not the primary transducers of sleep drive as hypothesized (Basheer et al., 2002).

The role of $\mathrm{AD}$ in regulating sleep homeostasis grew out of findings that systemic or intracerebroventricular administration of $\mathrm{AD}$ promoted sleep and decreased the waking state (Radulovacki et al., 1984; Ticho and Radulovacki, 1991). $\mathrm{AD}$ is a byproduct of cellular metabolism, and the increased cellular activity during waking could release $\mathrm{AD}$, which could gradually begin to inhibit the waking neurons. Consistent with a wake-related increase in cellular activity, there is a significant diurnal variation in $\mathrm{AD}$ levels in the hippocampus (Huston et al., 1996) and the BF (Murillo-Rodriguez et al., 2004) of rodents, with high $\mathrm{AD}$ levels during the lights-off period (when nocturnal rodents are awake) compared with the lights-on period. When waking is prolonged, AD levels also increase in the BF and cortex (Strecker et al., 2000; Murillo-Rodriguez et al., 2004). The BF is unique with respect to other arousal areas in that it is only here that $\mathrm{AD}$ triggers sleep relative to other regions (Strecker et al., 2000). The BF exhibits a diurnal rhythm in the activity of $\mathrm{AD}$-metabolizing enzymes (Mackiewicz et al., 2003). Specifically, activity of cytosolic 5' nucleotidase, the $\mathrm{AD}$-synthesizing enzyme, are higher at night relative to the day, whereas levels of adenosine deaminase (ADA), the AD-degrading enzyme, declines at night (Mackiewicz et al., 2003). Levels of $5^{\prime}$-nucleotidase are higher in the BF relative to the cortex (Alanko et al., 2003). The increase in activity of cytosolic 5' -nucleotidase relative to ADA could increase AD levels, which could then inhibit the wake-active BF neurons. BF wakeactive neurons are inhibited by local perfusion of AD (Thakkar et al., 2003a).

Although $\mathrm{AD}$ levels increase with waking in the $\mathrm{BF}$, is it correlative? Our findings indicate that it is correlated to waking, most likely released as a result of the increased activity of the BF cholinergic neurons. Thus, the increased AD in the BF, cortex, hippocampus, and striatum noted by several investigators (Huston et al., 1996; Strecker et al., 2000), including our group (Murillo-Rodriguez et al., 2004), is correlated with the wake-

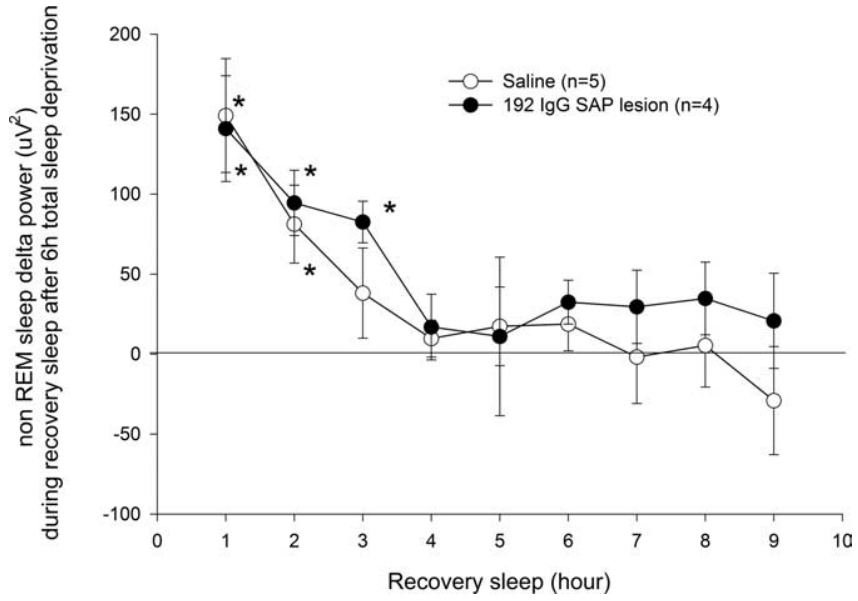

Figure 4. EEG delta power (EEG $0.3-4 \mathrm{~Hz}$ ) during recovery sleep after $6 \mathrm{~h}$ of total sleep deprivation. The delta power was determined in non-REM sleep during baseline and recovery sleep, and each data point represents the average difference from baseline (0 line on the $y$-axis). Delta power, a measure of sleep drive, was highest in both groups during the first hour of recovery sleep and then progressively declined to baseline levels. ${ }^{*} p<0.05$, significant difference compared with baseline. 


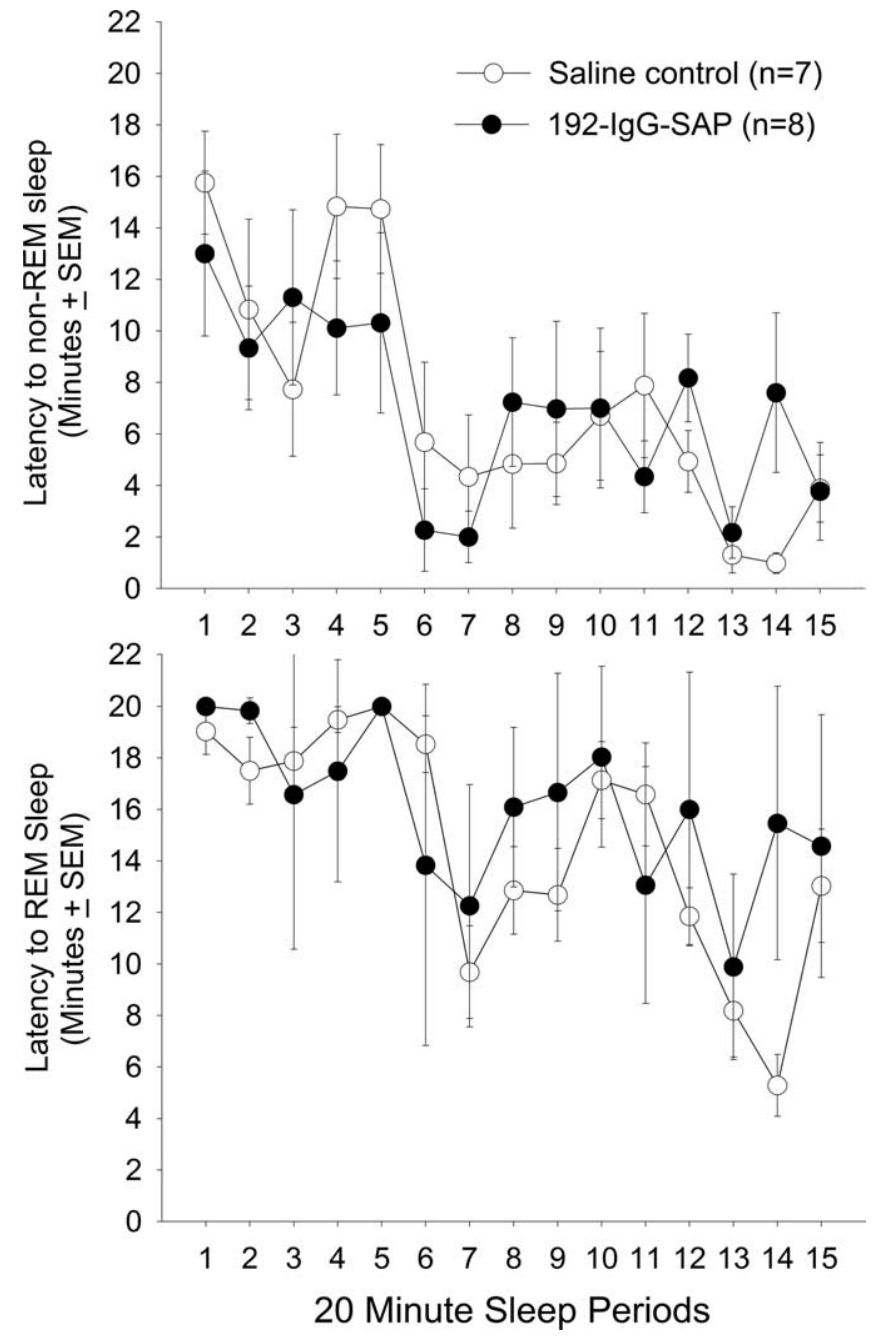

Figure 5. Time to onset of non-REM and REM sleep after 20 min periods of wake. Two hours after the start of the lights-on cycle, rats were kept awake for $20 \mathrm{~min}$ and then allowed to sleep for $20 \mathrm{~min}$. This alternating regimen of $20 \mathrm{~min}$ wake and $20 \mathrm{~min}$ sleep periods was continued throughout the lights-on period. The graph summarizes the time to onset of non-REM and REM sleep during the 20 min sleep periods. There were no significant differences between the control and 192-IgG-Sap groups.

related activity of the surrounding neurons. In the only study in humans (Zeitzer et al., 2006), AD levels did not increase with $40 \mathrm{~h}$ prolonged waking in the amygdala, hippocampus, and cortex. In the $\mathrm{BF}$, the activity of the cholinergic neurons appears to be the main source of $\mathrm{AD}$ release because, when they are eliminated, $\mathrm{AD}$ levels do not increase. Glia may release adenosine (Parkinson and Xiong, 2004), but, in lesioned rats, it is not sufficient to offset the decline. Adenosine reuptake in neurons or glia may change as a result of the lesion, but it would have to have increased significantly to account for the lack of change in extracellular adenosine levels in lesioned rats.

If $\mathrm{AD}$ levels do not increase with prolonged waking in lesioned rats, is the sleep drive intact? In the present study, established paradigms demonstrated that sleep homeostasis was intact in lesioned rats. In the first paradigm, rats were kept awake for 6 or $12 \mathrm{~h}$ and the amount of ensuing sleep was determined. Lesioned rats had as robust a sleep rebound as the control rats, indicting an intact response to sleep loss in the lesioned rats. Moreover, the lesioned rats had increased EEG delta power after $6 \mathrm{~h}$ sleep loss. In the second paradigm, a rodent version of the MSLT was used to

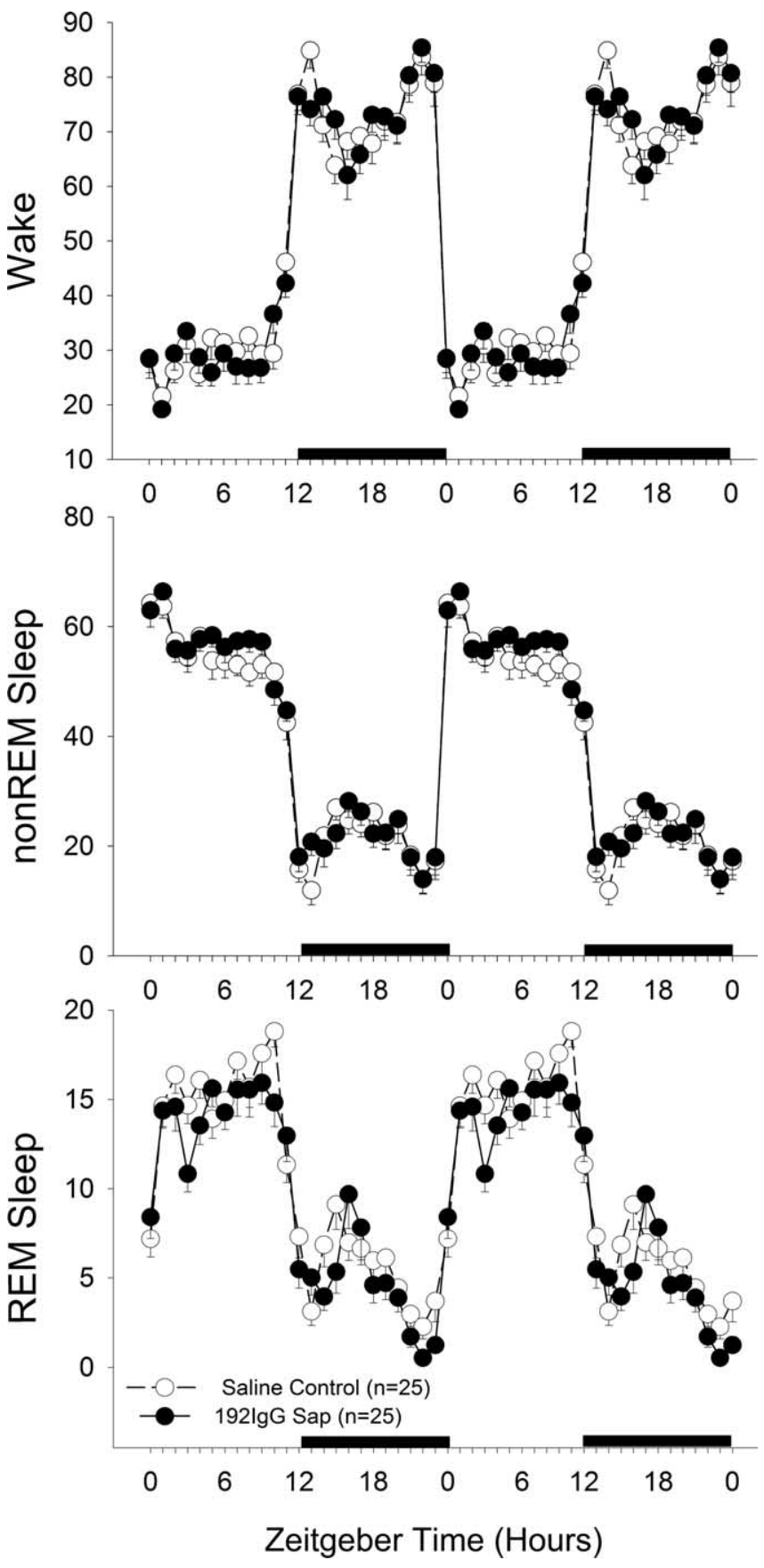

Figure 6. Sleep-wake states after 192-lgG-Sap lesions. Mean \pm SEM percentage of wake, non-REM sleep, and REM sleep in saline-treated and 192-lgG-Sap-treated rats that had $95 \%$ loss of the BF cholinergic neurons. Two weeks after administration of 192-lgG-Sap, sleep was recorded over a continuous $48 \mathrm{~h}$ period, and the data were averaged hourly to yield a $24 \mathrm{~h}$ plot. The $24 \mathrm{~h}$ data are double plotted to better reveal the diurnal rhythm of the sleep-wake cycle. The black bar represents the $12 \mathrm{~h}$ lights-off period. There were no significant differences between the two groups.

assess the sleep drive. In humans, short MSLT scores indicate heightened sleep drive (Carskadon et al., 1986), and, in our study, the lesioned rats had latencies to non-REM and REM sleep similar to control rats. Together, these studies indicate an intact sleep drive in BF cholinergic lesioned rats.

Because the lesioned rats had normal amounts of sleep, we investigated whether sleep could be induced by the noncholinergic neurons in the $\mathrm{BF}$, some of which are wake active ( $\mathrm{Za}$ - 
Table 4. Average \pm SEM percentage of sleep-wake states over a $24 \mathrm{~h}$ period 2 weeks after administration of saline or 192-IgG-Sap

\begin{tabular}{lllll}
\hline & \multicolumn{1}{l}{ REM } & NREM & Wake & Total sleep \\
\hline Saline $(n=25)$ & $10.25(0.31)$ & $38.41(1.52)$ & $51.34(1.40)$ & $48.66(1.40)$ \\
192-IgG-Sap $(n=25)$ & $8.81(0.57)$ & $39.50(1.59)$ & $51.70(1.50)$ & $48.31(1.50)$ \\
\hline
\end{tabular}

There were no significant differences between the two groups.

Table 5. Percentage of sleep-wake states during the lights-on and lights-off periods 2 weeks after administration of saline or 192-IgG-Sap

\begin{tabular}{lllll}
\hline & REM & NREM & Wake & Total sleep \\
\hline Lights-on & & & & \\
$\quad$ Saline $(n=25)$ & $14.86(0.49)$ & $55.18(1.74)$ & $29.97(1.70)$ & $70.04(1.70)$ \\
$\quad$ 192-IgG-Sap $(n=25)$ & $13.43(0.80)$ & $57.23(1.43)$ & $29.34(1.42)$ & $70.66(1.42)$ \\
$\begin{array}{l}\text { Lights-off } \\
\quad \text { Saline }(n=25)\end{array}$ & & & & \\
192-IgG-Sap $(n=25)$ & $4.32(0.52)$ & $21.83(1.59)$ & $72.45(1.67)$ & $27.55(1.67)$ \\
\end{tabular}

The numbers represent averages \pm SEM over the $12 \mathrm{~h}$ lights-on and lights-off periods. There were no significant differences between the two groups.

borszky and Duque, 2003). The adenosine $A_{1}$ receptor-specific agonist $\mathrm{CHA}$ was administered to the $\mathrm{BF}$, and, in rats with lesions of the $\mathrm{BF}$ cholinergic neurons, it was effective in inducing sleep. Thus, our findings demonstrate that $\mathrm{A}_{1}$ receptors on noncholinergic neurons are able to induce sleep. This finding does not support the contention of two recent studies that the $\mathrm{A}_{1}$ receptor on the $\mathrm{BF}$ cholinergic neurons was the key to transmitting the signal by adenosine for sleepiness. In one study, adenosine, acting via the $A_{1}$ receptor, stimulated calcium release in cholinergic but not noncholinergic neurons (Basheer et al., 2002). In the second study, perfusion of adenosine $A_{1}$ receptor antisense into the $B F$ reduced non-REM sleep and EEG delta power (Thakkar et al., 2003b). Neither study investigated whether sleep was changed after lesion of the $\mathrm{BF}$ cholinergic neurons, which left open the possibility raised by both studies that $A_{1}$ receptors on noncholinergic neurons could affect sleep.

Normal sleep induction in the lesioned rats could also arise via the $\mathrm{A}_{2 \mathrm{a}}$ receptor. Mice lacking the $\mathrm{A}_{2 \mathrm{a}}$ receptor sleep less, including after sleep deprivation (Urade et al., 2003). Infusion of the highly selective $A_{2 \mathrm{~A}}$ agonist CGS21680 (2-[p-(2-carboxyethyl) phenethylamino] $-5^{\prime}-N$-ethylcarboxamido adenosine) into the rostral BF increases both non-REM and REM sleep (Satoh et al., 1999) and increases c-Fos in sleep-active neurons of the ventral lateral preoptic area (VLPO) (Scammell et al., 2001). A direct excitatory effect of $\mathrm{A}_{2 \mathrm{a}}$ receptor stimulation on a subset of VLPO neurons was recently demonstrated (Gallopin et al., 2005). Caffeine, an $\mathrm{AD}$ receptor antagonist, may exert its powerful wakepromoting effects (Huang et al., 2005) via the $\mathrm{A}_{2 \mathrm{a}}$ receptor. Caffeine may also reduce the hypnotic effects of alcohol via this receptor (El Yacoubi et al., 2003). Thus, our findings do not negate the overall hypothesis of adenosine and sleep homeostasis, but they reject the role of the $\mathrm{BF}$ cholinergic neurons in this process. Elsewhere in the brain, including in the subarachnoid space and the adjoining ventral rostral forebrain, adenosine may exert its soporific effects as hypothesized (Urade et al., 2003).

The $\mathrm{BF}$ contains a heterogeneous population of neurons, and the neurotoxin 192-IgG-Sap was used to eliminate a phenotype of neurons hypothesized to be central to the regulation of sleep homeostasis. The 192-IgG-Sap kills BF cholinergic neurons by binding to the p75 NGF receptor found on these neurons (Book et al., 1994). The preferred method of delivery of the toxin is intracerebroventricularly, and the lesion is complete by $7 \mathrm{~d}$ after injection (Waite, 2005). There is an $80-90 \%$ reduction in ChAT
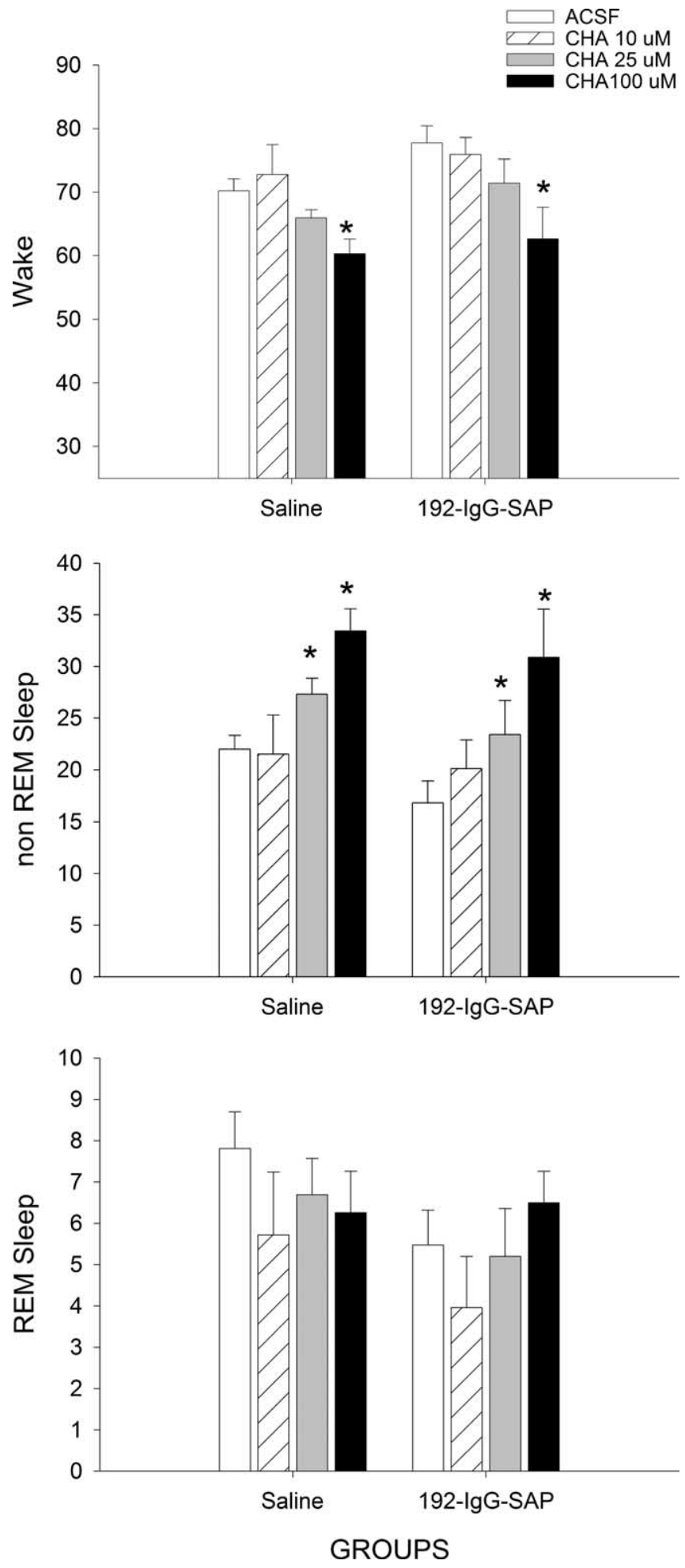

Figure 7. Effects of the adenosine $A_{1}$ receptor agonist CHA on wake, non-REM sleep, and REM sleep. Different concentrations of CHA $(10,25$, and $100 \mu \mathrm{M})$ or aCSF were infused via microdialysis into the basal forebrain for $12 \mathrm{~h}$ at the start of the lights-off period, and sleep was recorded during the drug infusion period. Data represent the mean \pm SEM percentage of wake, non-REM sleep, and REM sleep in saline- and 192-IgG-Sap-treated rats that had $95 \%$ loss of the $\mathrm{BF}$ cholinergic neurons. ${ }^{*} p<0.05$, significant difference compared with the respective aCSF of each group. The sample size for the saline group was as follows: aCSF, $n=9$; CHA at $10 \mu \mathrm{m}, n=$ 7; CHA at $25 \mu \mathrm{M}, n=9$; CHA at $100 \mu \mathrm{M}, n=9$. The sample size for the 192-lgG-Sap group was as follows: aCSF, $n=12$; CHA at $10 \mu \mathrm{m}, n=5$; CHA at $25 \mu \mathrm{m}, n=12$; CHA at $100 \mu \mathrm{M}, n=12$. 
activity in the cortex and hippocampus (Waite, 2005). By comparison, excitotoxins produce only a $16-44 \%$ reduction (Waite, 2005). In the ventral pallidum and sublenticular substantia innominata (caudal portions of $\mathrm{Ch} 4$ ) some of the cholinergic neurons [7.1\% by one estimate (Woolf et al., 1989)] do not contain the p75 NGF receptor and are spared by the toxin (Heckers et al., 1994). These ChAT-positive/p75negative neurons project to the amygdala (Hecker and Mesulam, 1994). Thus, only a very small minority of the BF cholinergic neurons does not contain the p75 NGF receptor. Ibotenic acid, an excitotoxin, which lesions these and other noncholinergic neurons, increases slow waves in the EEG (1-4 Hz) when applied to the SI (Buzsaki et al., 1988). However, because AD does not increase with prolonged waking, the minority of surviving cholinergic neurons projecting to the amygdala appear not to contribute significantly to AD. These surviving neurons are also unlikely to regulate sleep homeostasis, at least not through adenosine, because in humans adenosine levels in the amygdala do not increase with $40 \mathrm{~h}$ waking (Zeitzer et al., 2006).

The BF contains other neuronal subtypes, such as neurotensin, galanin, somatostatin, parvalbumin, NADPH, and NPY, but they do not possess the p75 receptor and the toxin does not kill them (Wenk et al., 1994). In the brainstem, there are neurons that contain the p75 receptor but they are not killed (Heckers et al., 1994). The only other neurons that are killed are the cerebellar Purkinje cells, which contain the p75 receptor (Heckers et al., 1994). However, loss of these neurons is unlikely to impact BF $\mathrm{AD}$ and homeostatic regulation of sleep because total cerebellectomy does not decrease total amount of sleep (Paz et al., 1982).

The BF cholinergic neurons share a reciprocal connection with the orexin/hypocretin neurons in the lateral hypothalamus (Sakurai et al., 2005). Because there was no change in the amount of sleep-wake in the cholinergic neuron lesioned rats, we suggest that waking is not attributable to the BF cholinergic neurons driving the orexin/hypocretin neurons. The latter neurons are selectively active during waking (Lee et al., 2005b; Mileykovskiy et al., 2005), and they continue to be the only group of wakeactive neurons whose lesion significantly alters sleep-wake regulation.

\section{References}

Alanko L, Heiskanen S, Stenberg D, Porkka-Heiskanen T (2003) Adenosine kinase and $5^{\prime}$-nucleotidase activity after prolonged wakefulness in the cortex and the basal forebrain of rat. Neurochem Int 42:449-454.

Basheer R, Arrigoni E, Thatte HS, Greene RW, Ambudkar IS, McCarley RW (2002) Adenosine induces inositol 1,4,5-trisphosphate receptormediated mobilization of intracellular calcium stores in basal forebrain cholinergic neurons. J Neurosci 22:7680-7686.

Bassant MH, Apartis E, Jazat-Poindessous FR, Wiley RG, Lamour YA (1995) Selective immunolesion of the basal forebrain cholinergic neurons: effects on hippocampal activity during sleep and wakefulness in the rat. Neurodegeneration 4:61-70.

Book AA, Wiley RG, Schweitzer JB (1994) 192 IgG-saporin. I. Specific lethality for cholinergic neurons in the basal forebrain of the rat. J Neuropathol Exp Neurol 53:95-102.

Borbely AA, Tobler I, Hanagasioglu M (1984) Effect of sleep deprivation on sleep and EEG power spectra in the rat. Behav Brain Res 14:171-182.

Buzsaki G, Bickford RG, Ponomareff G, Thal LJ, Mandel R, Gage FH (1988) Nucleus basalis and thalamic control of neocortical activity in the freely moving rat. J Neurosci 8:4007-4026.

Carskadon MA, Dement WC, Mitler MM, Roth T, Westbrook PR, Keenan S (1986) Guidelines for the multiple sleep latency test (MSLT): a standard measure of sleepiness. Sleep 9:519-524.

Celesia GG, Jasper HH (1966) Acetylcholine released from cerebral cortex in relation to state of activation. Neurology 16:1053-1063.

El Yacoubi M, Ledent C, Parmentier M, Costentin J, Vaugeois JM (2003)
Caffeine reduces hypnotic effects of alcohol through adenosine A2A receptor blockade. Neuropharmacology 45:977-985.

Fredholm BB (1995) Astra Award Lecture. Adenosine, adenosine receptors and the actions of caffeine. Pharmacol Toxicol 76:93-101.

Gallopin T, Luppi PH, Cauli B, Urade Y, Rossier J, Hayaishi O, Lambolez B, Fort P (2005) The endogenous somnogen adenosine excites a subset of sleep-promoting neurons via A2A receptors in the ventrolateral preoptic nucleus. Neuroscience 134:1377-1390.

Gerashchenko D, Shiromani PJ (2004) Different neuronal phenotypes in the lateral hypothalamus and their role in sleep and wakefulness. Mol Neurobiol 29:41-59.

Greco MA, Lu J, Wagner D, Shiromani PJ (2000) c-Fos expression in the cholinergic basal forebrain after enforced wakefulness and recovery sleep. NeuroReport 11:437-440.

Hecker S, Mesulam MM (1994) Two types of cholinergic projections to the rat amygdala. Neuroscience 60:383-397.

Heckers S, Ohtake T, Wiley RG, Lappi DA, Geula C, Mesulam MM (1994) Complete and selective cholinergic denervation of rat neocortex and hippocampus but not amygdala by an immunotoxin against the p75 NGF receptor. J Neurosci 14:1271-1289.

Huang ZL, Qu WM, Eguchi N, Chen JF, Schwarzschild MA, Fredholm BB, Urade Y, Hayaishi O (2005) Adenosine A2A, but not A1, receptors mediate the arousal effect of caffeine. Nat Neurosci 8:858-859.

Huston JP, Haas HL, Boix F, Pfister M, Decking U, Schrader J, Schwarting RK (1996) Extracellular adenosine levels in neostriatum and hippocampus during rest and activity periods of rats. Neuroscience 73:99-107.

Jasper HH, Tessier J (1971) Acetylcholine liberation from cerebral cortex during paradoxical (REM) sleep. Science 172:601-602.

Jones BE (2003) Arousal systems. Front Biosci 8:S438-S451.

Jones BE (2004) Activity, modulation and role of basal forebrain cholinergic neurons innervating the cerebral cortex. Prog Brain Res 145:157-169.

Kapas L, Obal Jr F, Book AA, Schweitzer JB, Wiley RG, Krueger JM (1996) The effects of immunolesions of nerve growth factor-receptive neurons by 192 IgG-saporin on sleep. Brain Res 712:53-59.

LaJambe CM, Kamimori GH, Belenky G, Balkin TJ (2005) Caffeine effects on recovery sleep following $27 \mathrm{~h}$ total sleep deprivation. Aviat Space Environ Med 76:108-113.

Latini S, Pedata F (2001) Adenosine in the central nervous system: release mechanisms and extracellular concentrations. J Neurochem 79:463-484

Lee MG, Hassani OK, Alonso A, Jones BE (2005a) Cholinergic basal forebrain neurons burst with theta during waking and paradoxical sleep. J Neurosci 25:4365-4369.

Lee MG, Hassani OK, Jones BE (2005b) Discharge of identified orexin/ hypocretin neurons across the sleep-waking cycle. J Neurosci 25:6716-6720.

Mackiewicz M, Nikonova EV, Zimmerman JE, Galante RJ, Zhang L, Cater JR, Geiger JD, Pack AI (2003) Enzymes of adenosine metabolism in the brain: diurnal rhythm and the effect of sleep deprivation. J Neurochem 85:348-357.

Manns ID, Alonso A, Jones BE (2000) Discharge properties of juxtacellularly labeled and immunohistochemically identified cholinergic basal forebrain neurons recorded in association with the electroencephalogram in anesthetized rats. J Neurosci 20:1505-1518.

Mileykovskiy BY, Kiyashchenko LI, Siegel JM (2005) Behavioral correlates of activity in identified hypocretin/orexin neurons. Neuron 46:787-798.

Murillo-Rodriguez E, Blanco-Centurion C, Gerashchenko D, Salin-Pascual RJ, Shiromani PJ (2004) The diurnal rhythm of adenosine levels in the basal forebrain of young and old rats. Neuroscience 123:361-370.

Parkinson FE, Xiong W (2004) Stimulus- and cell-type-specific release of purines in cultured rat forebrain astrocytes and neurons. J Neurochem 88:1305-1312.

Paxinos G, Watson C (2006) The rat brain in stereotaxic coordinates. New York: Academic.

Paz C, Reygadas E, Fernandez-Guardiola A (1982) Sleep alterations following total cerebellectomy in cats. Sleep 5:218-226.

Porkka-Heiskanen T (1999) Adenosine in sleep and wakefulness. Ann Med 31:125-129.

Porkka-Heiskanen T, Strecker RE, Thakkar M, Bjorkum AA, Greene RW, McCarley RW (1997) Adenosine: a mediator of the sleep-inducing effects of prolonged wakefulness. Science 276:1265-1268.

Porkka-Heiskanen T, Strecker RE, McCarley RW (2000) Brain sitespecificity of extracellular adenosine concentration changes during sleep 
deprivation and spontaneous sleep: an in vivo microdialysis study. Neuroscience 99:507-517.

Porkka-Heiskanen T, Alanko L, Kalinchuk A, Stenberg D (2002) Adenosine and sleep. Sleep Med Rev 6:321-332.

Portas CM, Thakkar M, Rainnie DG, Greene RW, McCarley RW (1997) Role of adenosine in behavioral state modulation: a microdialysis study in the freely moving cat. Neuroscience 79:225-235.

Radulovacki M, Virus RM, Djuricic-Nedelson M, Green RD (1984) Adenosine analogs and sleep in rats. J Pharmacol Exp Ther 228:268-274.

Rainnie DG, Grunze HC, McCarley RW, Greene RW (1994) Adenosine inhibition of mesopontine cholinergic neurons: implications for EEG arousal. Science 263:689-692.

Rasmusson DD, Clow K, Szerb JC (1992) Frequency-dependent increase in cortical acetylcholine release evoked by stimulation of the nucleus basalis magnocellularis in the rat. Brain Res 594:150-154.

Sakurai T, Nagata R, Yamanaka A, Kawamura H, Tsujino N, Muraki Y, Kageyama H, Kunita S, Takahashi S, Goto K, Koyama Y, Shioda S, Yanagisawa M (2005) Input of orexin/hypocretin neurons revealed by a genetically encoded tracer in mice. Neuron 46:297-308.

Satoh S, Matsumura H, Koike N, Tokunaga Y, Maeda T, Hayaishi O (1999) Region-dependent difference in the sleep-promoting potency of an adenosine A2A receptor agonist. Eur J Neurosci 11:1587-1597.

Scammell TE, Gerashchenko DY, Mochizuki T, McCarthy MT, Estabrooke IV, Sears CA, Saper CB, Urade Y, Hayaishi O (2001) An adenosine A2a agonist increases sleep and induces Fos in ventrolateral preoptic neurons. Neuroscience 107:653-663.

Semba K (2000) Multiple output pathways of the basal forebrain: organization, chemical heterogeneity, and roles in vigilance. Behav Brain Res 115:117-141

Shiromani PJ, Velazquez-Moctezuma J, Overstreet D, Shalauta M, Lucero S, Floyd C (1991) Effects of sleep deprivation on sleepiness and increased REM sleep in rats selectively bred for cholinergic hyperactivity. Sleep 14:116-120.

Shiromani PJ, Lu J, Wagner D, Thakkar J, Greco MA, Basheer R, Thakkar M (2000) Compensatory sleep response to $12 \mathrm{~h}$ wakefulness in young and old rats. Am J Physiol Regul Integr Comp Physiol 278:R125-R133.

Strecker RE, Morairty S, Thakkar MM, Porkka-Heiskanen T, Basheer R, Dauphin LJ, Rainnie DG, Portas CM, Greene RW, McCarley RW (2000) Adenosinergic modulation of basal forebrain and preoptic/anterior hypothalamic neuronal activity in the control of behavioral state. Behav Brain Res 115:183-204.
Szerb JC (1967) Cortical acetylcholine release and electroencephalographic arousal. J Physiol (Lond) 192:329-343.

Szymusiak R, Alam N, McGinty D (2000) Discharge patterns of neurons in cholinergic regions of the basal forebrain during waking and sleep. Behav Brain Res 115:171-182.

Thakkar MM, Delgiacco RA, Strecker RE, McCarley RW (2003a) Adenosinergic inhibition of basal forebrain wakefulness-active neurons: a simultaneous unit recording and microdialysis study in freely behaving cats. Neuroscience 122:1107-1113.

Thakkar MM, Winston S, McCarley RW (2003b) A receptor and adenosinergic homeostatic regulation of sleep-wakefulness: effects of antisense to the $A_{1}$ receptor in the cholinergic basal forebrain. J Neurosci 23:4278-4287.

Ticho SR, Radulovacki M (1991) Role of adenosine in sleep and temperature regulation in the preoptic area of rats. Pharmacol Biochem Behav 40:33-40

Urade Y, Eguchi N, Qu WM, Sakata M, Huang ZL, Chen JF, Schwarzschild MA, Fink JS, Hayaishi O (2003) Sleep regulation in adenosine A2A receptor-deficient mice. Neurology 61:S94-S96.

Waite JJ (2005) Biochemical, physiological and behavioral characterization of the cholinergic basal forebrain lesion produced by $192-\operatorname{IgG}$-saporin. In: Molecular neurosurgery with targeted neurotoxins (Wiley RG, Lappi DA, eds), pp 31-58. Totowa, NJ: Humana.

Wenk GL, Stoehr JD, Quintana G, Mobley S, Wiley RG (1994) Behavioral, biochemical, histological, and electrophysiological effects of 192 IgGsaporin injections into the basal forebrain of rats. J Neurosci 14:5986-5995.

Woolf NJ, Gould E, Butcher LL (1989) Nerve growth factor receptor is associated with cholinergic neurons of the basal forebrain but not the pontomesencephalon. Neuroscience 30:143-152.

Wyatt JK, Cajochen C, Ritz-De Cecco A, Czeisler CA, Dijk DJ (2004) Lowdose repeated caffeine administration for circadian-phase-dependent performance degradation during extended wakefulness. Sleep 27:374-381.

Zaborszky L, Duque A (2003) Sleep-wake mechanisms and basal forebrain circuitry. Front Biosci 8:d1146-d1169.

Zeitzer JM, Morales-Villagran A, Maidment NT, Behnke EJ, Ackerson LC, Lopez-Rodriguez F, Fried I, Engel Jr J, Wilson CL (2006) Extracellular adenosine in the human brain during sleep and sleep deprivation: an in vivo microdialysis study. Sleep 29:455-461. 